\title{
Book Review: The Internet Myth: From The Internet Imagi- nary to Network Ideologies by Paolo Bory
}

\author{
Jamie Ranger
}

St. Hugh's College, University of Oxford, Oxford, UK, james.ranger@sthughs.ox.ac.uk

\begin{abstract}
Jamie Ranger reviews Paolo Bory's The Internet Myth: From The Internet Imaginary to Network Ideologies. Bory contends that there is a dominant narrative within Internet studies that networks, by virtue of their being networks, are the main agents of social, economic and political change. He argues that this myth is embedded in the foundational imaginaries that were constructed around the Internet in the 1990s and that such an understanding forecloses and provincializes human-centred collective action towards alternative possibilities.
\end{abstract}

Keywords: network ideologies, Internet imaginaries, Internet history, Internet myth, network imaginary, the Web

Acknowledgement: Thanks to Andrew Lockett at University of Westminster Press for sending a review copy.

I believe that Paolo Bory would wish the reader to take the following ideas away with them from his insightful debut: firstly, the Internet of today is one of many possible versions and the synonymity with which we talk about the Internet and the World Wide Web is a product of contingency rather than technological determinism; secondly, the way in which we think about the history of the Internet and the locus of its origins is often embedded in our perception of what we think of the Internet at present and how we speculate on its future; and finally, and perhaps most importantly, we ought to challenge the network ideology, 'the idea that networks, by themselves, are the main agents of social, economic, political and cultural change' (1).

Bory's intervention is necessitated by a recent transformation in the Internet myth, specifically "the conceptual shift from a technical object (the network as infrastructure) to an ideological reference (the network as the elective model for the organization of societies" (3). Bory argues that the theoretical framing of his book relies on three main assumptions: that there is more than one Internet and that this notion has been historically underexplored; that the development of any computer network relies on the socio-cultural context in which it is embedded; and finally that the mediated and culturally communicated framing of a network is itself part of the broader narrative of the technical object: "the Internet and the Web both convey and are themselves narratives; they communicate something to us" (4).

Bory argues that there are three predominant foundational Internet narratives: the digital library metaphor; the military origin story; and the communitarian ideology (10). The digital library metaphor theorises a future technology that utilises networks to solve the difficulty of finding a method of information organisation and retrieval that has precluded the technical possibility of a universal library. This narrative arguably begins with US scientist Vannevar Bush in 1945 forecasting that 'wholly new forms of Encyclopedias will appear' (11), through to Tim Berners-Lee, inventor of the World Wide 
Web, sharing a continuity of commitment to knowledge dissemination. The military narrative of the origin of the Internet, argued with support from Tung-Hui Hu that it is overplayed, is compared to prior paranoid myths surrounding the radio and the cinema: "they all tell of a powerful new technological form able to change the perception of space and the very meaning of mediated communication" (14). The communitarian ideology is committed to the view that the Internet truly emerged through its gradual democratisation, starting as a limited technology used by military and academic specialists and "then, in a second stage, users seized and changed the very meanings of these technological artefacts by using them for unexpected purposes such as interpersonal communication or playful activities" (14).

In the 1990s, these three interrelated and convergent narrative threads are woven together in support of either the 'cyberspace' or the 'information superhighway' framing of the Internet. With support from Vincent Mosco, Bory argues that cyberspace "was largely perceived as the unstoppable cause of three imminent radical changes: the end of history, the end of physical distance, and the end of traditional political systems" (17). Cyberspace was ostensibly the spatial imaginary for an emergent globalised system of computer-mediated communication, whereas the information superhighway was a "metaphor of political and economic progress from above" (19). Bory places cyberspace and the information superhighway at opposite ends of an idealistic/pragmatic spectrum, yet both conceptualisations are attributed certain 'post-political', 'postideological', 'post-historical' qualities symptomatic of the neoliberal perspective hegemonic of late-90s Western capitalism. At this juncture, it is pertinent to note that neither 'neoliberalism' nor 'capitalism' are seriously interrogated in the text, but given the attentiveness to the materiality of infrastructure networks and the political economy of telecommunications, we can assume this to be an intentional research decision, rather than a methodological oversight. As Bory will later attest, with excellent case studies in support, there is more to the story of the Internet than 'the Americans got there first'.

One of the strongest of Bory's contentions is that academics ought to focus on the history of networks when wishing to uncover an account of the Internet's emergence, given the prevalence of mythology to colour our judgements of what the Internet is or is supposed to be. For example, Paul Baran's essay on three types of network (centralised, decentralised and distributed) was popularised and folded into an idealising rhetoric. The distributed model that shows the most equitable horizontal linkages between nodes is often presumed to be a) analogous to the democratisation of organisational power, b) the original intentional model of distribution for the Internet and/or c) the way the Internet used to be before the emergence of Silicon Valley. Bory, quoting Tung-Hui Hu, reminds us that "the distributed model, designed by Baran, was never built" (26): the kind of Internet many of us would consider to be the Internet in its purest, de-capitalised form, is actually a system that has yet to be realised. A democratic Internet is not a relic to be uncovered by a critical examination of the past, nor solely a form of the Internet suppressed by the powers that be, but a form to be concretised and strived towards as one of many possible Internet futures.

I must confess that I found the opening section of the second chapter to be the weakest: Bory applies Joseph Campbell's monomyth structure to biographical accounts of Tim Berners-Lee, the inventor of the World Wide Web. The justification for such an enterprise, whilst an entertaining read, is that "the figure of Berners-Lee, who is depicted as an under-sung and humble hero of the digital revolution, amplifies features such as the neutrality and the implicit goodness of the Web" (51). I find this may well be true for those accounts leaning hagiographically on personal heroes for their 
own advocacy of the Internet as a revolutionary technology, but given the relative obscurity of Berners-Lee outside of our discipline (on an anecdotal level, I once won a pub quiz for knowing his name), I question the potency of his story in the broader Internet imaginary, although others may disagree. The ubiquity of the monomyth as an instructional narrative model (especially in American screenwriting and creative writing manuals) is arguably an equally plausible explanation for its mapping of both BernersLee and popular narratives of the Web. Campbell himself argues that the monomyth is the most consistent narrative structure in civilization, after all. The chapter concludes by arguing that "to delegate the narrative voice of the Web's history to a limited number of key actors [...] means to underestimate the multiplicity of narratives and paths that have determined its very meaning and its role" (65), and I completely agree: we cannot excavate old interviews with a young Berners-Lee to discover the 'true' or 'pure' intentions for the Web, as if ascertaining the artistic legacy of an auteur. Furthermore, the way that Berners-Lee often refers to himself (albeit with humility and self-awareness) as an instrument of 'capital-H' History often serves a deterministic understanding of the Web as the inevitable means by which the Internet would become fully realised, thus precluding from a wider historical discourse those alternatives Bory wishes to explore.

The third chapter explores two Italian case studies in alternative network technologies: the Socrate and Iperbole projects. Telecom Italia's ambitious 1994 project Socrate, an attempt to build a nationwide fibre-optic broadband network infrastructure, ended as an expensive failure. Amongst other reasons for its shortcomings was the sheer disruption of social life and habits in urban areas involved in building infrastructure projects, all against the ticking clock of future innovations that could render the project obsolete before its completion. As Bory is apt to note, the case study bears witness to the oft-underexplored materiality of the digital world. Whilst contemporary technologies thrive on the rhetoric of metaphorical disruption, the physical disruption of everyday life in service of a speculative and uncertain technological commitment meant simply that the technology did not meet its market. The public imagination had yet to be captured by the prospects of cyberspace, and instead saw their own public space being compromised by a company digging holes. As I read this passage, I immediately compared the purported indifference to Socrate to the erection of $5 \mathrm{G}$ phone masts during the coronavirus lockdown, where the imposition of technology by external forces for the greater good in a modern context is met in certain reactionary corners of the Internet with conspiratorial paranoia.

The Iperbole project is a fascinating case study for those academics researching democracy and public space, e-democracy, and the relationship between digital and physical networks. Iperbole, a local network for citizens living in Bologna, was initially a runaway success, allowing individuals to post messages on various themed boards and discussion groups encouraging online civic participation. Bory notes that "the idea of a city that plays the role of an intermediary, we could say a medium, through which electronic democracy could take place, was particularly innovative and extremely powerful at the time" (89). Bory compares this explicitly political, participatory and interactive Internet with the passive consumerist vision of Socrate, "in which the citizen is conceived as a passive spectator of phenomena to which he is not stimulated to participate" (90).

In the final chapter, Bory argues that "the ideological force of the Internet myth and network ideologies lies in their simple explanation of networking as a solution to reduce complexity. According to network ideologies, structure, infrastructure and social structure converge in the network ideal" (117). The network imaginary, in a confusing and 
accelerating social world, serves to provide a safety net: the world may be chaotic, but this disorder can be organised and rearticulated through the efficient and clarifying power of networks. This imaginary suffers from technological determinism and harbours complacency surrounding future network innovations. Bory contends that "a collective imaginary stubbornly oriented towards the limitlessness of networking systems may compromise the collective capacity to change and co-shape the future by means of informed collective and political actions" (123). Bory concludes with an impassioned call for researchers to critically examine the extent to which actions have been falsely ascribed to technological infrastructures and their inevitable influence as a "step towards a human-centred vision that maintains a critical distance from the idealistic utopia of a promised net, an imaginary network that never existed" (126).

In terms of exciting further research avenues, Bory's work on Internet imaginaries lends itself to a critical examination of those theories intending to navigate surveillance and platform capitalism, the dominant models of thinking about digital media today, and whether those committed to challenging these power structures are overly reliant on a mythological version of the Internet. As much as we wish to resist those disproportionately powerful corporate forces that have centralised Internet activity and normalised social media monopolisation as hubs from which other resources are accessed, not to mention the data extraction and retention which goes along with such platform dominance, we must also be wary of the ways in which alternative arrangements may be considered plausible solely because they are consistent with historical imaginaries rather than concrete possibilities. Bory's intervention, therefore, is a necessary and timely corrective.

\section{References}

Bory, Paolo. 2020. The Internet Myth: From the Internet Imaginary to Network Ideologies. London: University of Westminster Press.

\section{About the Author}

\section{Jamie Ranger}

Jamie Ranger is a doctoral candidate at St. Hugh's College, University of Oxford in the Department of Politics \& IR. He writes on the politics of speed, technics, media, space and radical democratic theory. He tweets from @jamieandhisego. 